\title{
DIR®-informed approach to anxiety and trauma in school age children
}

\author{
Galina Itskovich \\ Interdisciplinary Council on Development and Learning \\ New York, USA
}

\begin{abstract}
As dwellers of our planet receive an overwhelming amount of information and live coverages of scary, traumatizing and horrifying events around the globe, anxiety takes the front seat in the clinical discourse. At the same time, children are even more susceptible to anxiety than adults, mainly because of lack of control over their lives, actual helplessness, operating largely on clues and adult whisper rather than on confirmed (and comprehended by them) facts; most of the time, they have no impact on own future. Excessive worry and uncertainty can manifest itself as aggression, "striking out", low frustration tolerance and impulsivity. Another, not less important, predictor of anxiety is the ability to selfregulate and the speed with which a child can recover from stress or perceived danger and, shutting down the initial response of hypervigilance, go back to the state of homeostasis.

Naturally, all the above greatly depends on individual history and patterns of resilience. Prior history of trauma is the most important marker of emerging symptoms of anxiety and anticipatory anxiety. Mechanisms of trauma processing, as well as family and individual history of trauma and vicarious traumatization should be closely examined in the process of assessment and addressed in psychotherapeutic treatment regardless of the nature and scope of presenting problems.
\end{abstract}

This paper examines presenting problems of latency age children, stemming from anxiety and/or psychological trauma. The author shares her experience of addressing the above issues in psychotherapeutic work using Developmental, Individual differences and Relationship based approach (DIR®). This diagnostic and treatment model defines and describes the hierarchy of developmental capacities humans are to achieve throughout their early, formative years, individual profile (unique ways of information processing) and employing affect based therapeutic interaction to promote the development of the above. Individual profile includes motor control, praxis, visual spatial capacities and integration of sensory information supplied by five organs of sense and vestibular, visceral and proprioceptive systems, language capacities, and affective relationships. DIR ${ }^{\circledR}$ can be utilized for the purpose of differential diagnosis, as well as an invaluable philosophical base. This diagnostic and treatment paradigm allows for comprehensive scrutiny of co-occurring problems, developmental capacities and a multitude of variations in sensory, medical, familial and environmental characteristics that serve as prequel to symptoms. Additionally, DIR ${ }^{\circledR}$ lends us a treatment philosophy that leaves room for the individuality of the child. Case examples illustrate application of DIR ${ }^{\circledR}$ and utilizing elements of the DIR Floortime.

Keywords: DIR ${ }^{\circledR}$, DIR Floortime, anxiety, school aged children, differential diagnosis, child psychotherapy. 


\section{Introduction}

The WHO (World Health Organization) states that anxiety disorders are the most prevalent mental disorders worldwide. 1 in 13 individuals globally suffers from anxiety. According to large population-based surveys, up to $33.7 \%$ of the population are affected by an anxiety disorder during their lifetime (Data and Statistics on Children's Mental Health, CDC). Among the U.S. children, 7.1\% aged 3-17 years (approximately 4.4 million) have diagnosed anxiety. The percentage of diagnosed children spikes by the age of 12 . Research by the National Institute of Mental Health shows that untreated children with anxiety disorders are at higher risk to perform poorly in school, miss out on important social experiences, and engage in substance abuse (Anxiety and Depression Association of America, 2019). To complicate this picture even more, let me add that in the era of globalization children face challenges that are unprecedented. Secondary trauma, or indirect exposure to trauma, the constant stream of breaking news and gruesome details that become available in real time via mass media/social media are superimposed on the actual trauma incurred during the upsurge in social unrest and local wars. As per UNICEF, nearly 31 million children were internally displaced worldwide in 2017; $20 \%$ were reported to suffer from PTSD. For many countries, heightened terrorist activity the way it's impacted many urban communities has been opening a new level of exposure to the unanticipated danger. At the same time, traumatic occurrences become more prevalent not only in urban but also in suburban communities, and recent wave of school shootings is a prime example of such. Increased frequency of natural disasters associated with the climate change also adds a layer of anxiety and becomes a potential source of trauma. As for the vicarious exposure, for example, computer games offer simulated disasters that can be (and are) experienced by players as immediate and real. The emotional landscape of our lives is changing daily under the influence of these unending hits and misses.

Considering all these factors, mental health practitioners tread through the newly discovered, vast plains. In addition to the usual palette of cases from the Anxiety Disorders cluster, there are more and more cases of anxiety with cooccurring trauma. Children are as susceptible to trauma but, because their coping mechanism is barely developed, their vulnerability is much greater than that of adults. The latency age population is the easiest to fall through the cracks because of the assumed uneventfulness of this developmental stage: these kids (supposedly) already mastered basic milestones yet had not moved into a hormonally driven turmoil of adolescence. Though, this group experiences their own unique emotional pressures, with very little emotional padding to take them through anxious, angry, terrifying thoughts, premonitions and fantasies. Coping strategies, neither healthy nor unhealthy, those that are available to the older age group, are not developed yet. While adults have some, albeit limited, measure of control (i.e., devising an escape plan, choosing to fight back, reaching for help), and they can also employ previous experience and mobilize existing coping mechanisms, children are left at the mercy of circumstances and their own selfregulating capacity.

Diagnostic and treatment framework offered by Developmental, Individual differences and Relationship based approach (DIR ${ }^{\circledR}$ and/or DIR Floortime), a method pioneered by S. Greenspan, can be effectively used in the assessment and 
treatment of this diverse, as we shall see, group. DIR ${ }^{\circledR}$ is a comprehensive, dynamic, child driven and affect driven developmentally based model that takes into account not only psychodynamic and behavioral manifestations but also biologically based individual differences, namely, sensory, language, cognition, motor skills, and assesses capacities of functional emotional development (FEDC). It also incorporates familial, cultural and community systems as they influence the child. Different level capacities will be mentioned throughout this paper wherever applicable.

\section{Neurobiology of the anxious and stressed brain}

Anxiety affects several systems in the brain, from neurotransmitters in the central nervous system (CNS) to the limbic system (hippocampus and amygdala). Top-down, cortex-based anxious thoughts have the potential to activate the amygdala, which, in turn, produces the physical, bottom-up response. Cerebral cortex helps us to interpret our current experiences and to make predictions about what is likely to happen in the future. The peripheral nervous system regulates and counteracts mechanisms of arousal and dampening. Also, in the last several decades, the role of the visceral vagal response (polyvagal theory of Stephen Porges) is being better understood, too. Whether it's load conditions that activate sympathetic response undermining the existing regulation system, or "improbable fears", in D. Winnicott's formulation, of the normal developmental trajectory, either pathway can be a primary source of anxiety. Symptoms of anxiety (fears, influx of anxious mood, worry, panic attacks) can be set off by the polyvagal response to the emotionally meaningful person's "irritated, overly loud voice, a "serious" (lowered corners of the mouth, frowning forehead) face" (Itskovich, 2019). These polyvagal signals increase heart rate. In fact, all emotional and affective states require specific physiological shifts to facilitate their expression and to reach their implicit goals (e.g., fight, flight, freeze, proximity, etc.). (Porges, 2009). Individual responses to SNS overload vary from anxiously controlling, to flooded, to hyper/hypovigilant (hypervigilant - on constant alert, hypovigilant - passive and detaching under stress).

Self-regulation, Capacity 1 on the DIR ${ }^{\circledR}$ scale of functional emotional development, comes to the forefront of treatment for anxiety. The modern take on neurodevelopment holds that self-regulation, a core capacity of human development, established early on via primary relationships, regulates functions of the amygdala (D. Siegel, 2011), while maladaptive, dysregulated responses to trauma activate sympathetic circuitry and actually contribute to amygdala shrinkage (Herrington et.al.2017). Emotion regulation and social affiliation are considered emergent properties of the regulatory functions served by the vagus. Deployment of the newer vagal system suppresses robust emotional reactions that characterize fight/flight/freeze response, a prerequisite for the emergence of complex social behavior. Through "characterizing how states of anxiety and a vulnerability to being anxious would be potentiated or dampened by different autonomic states" (Porges, 2009), we obtain greater degree of control over interventions aimed at dampening sympathetic tone or increasing sympathetic response.

\section{Clinical presentation of the anxious and stressed brain}


Because of the breadth of issues and multitude of problems that are covered by the DSM-5 anxiety cluster, as well as the purposes of this article, the author would like to concentrate on just a few. Overload of the ANS leads to disruptions not only in the fight/flight/freeze cycle, but also in the already existing attachment patterns. Attachment disruptions further contribute to clinical presentations of both post-traumatic and anxious etiology. According to the founders of the concept of mentalization, attachment trauma can further lead to a shutdown in mentalization, the mental ability to be curious and inquisitive about mental states in oneself and others (Bateman, Fonagy, 2006; Allen, Bateman, Fonagy, 2008). It becomes hard for the individual to take into account thoughts and feelings of the other and/or make accurate predictions of others' reaction or emotional response.

Another landmark feature of trauma-based anxiety is a quickly developing pattern of cognitive distortions. This leads to the "emotional reasoning" when past traumatic experience overrides the decision making, and the problem-solving capacity deteriorates as a result. An affected child tends to generalize negative experiences ("it always happens to me"), and discount positive ones, initiating self-defeating behaviors (Hecht (2013) confirms, "The right hemisphere has tendency to focus on negative information, whether that information is visual or auditory"). Black-and- white thinking (dividing the entire world into "I" and "they") comes into effect, which constitutes an arrest at the Functional Emotional Capacity 7. Affected individuals tend to "read the other person's mind" ("I know that you're going to say... etc."), always assuming the worst.

It is also important to appreciate and examine, as much as we humanly can, the factor of personal resilience. Beauchaine et. al. pose the question "why some emotionally labile individuals respond more often with appetitive (including fight) behaviors, as in the case of externalizing disorders, while others respond more often with aversive (including flight) behaviors, as in the case of internalizing disorders..." and further stipulate that "it is crucial to understand how to facilitate this innate capacity to formulate a situation-appropriate "resilient" response and restore sense of safety and security" $(2001,2002)$.

Oftentimes it is hard to decipher what came first, psychological trauma or anxiety, but the interplay of these two results in the most difficult clinical presentation. Regressive symptomatology, stupor, repetitive play or traumatic reenactment, hyperactivity, inactivity, withdrawal go hand in hand with anxiety symptoms. Children, regardless of their neurological makeup, may not verbally acknowledge their terror or persistent worry, but present with the range of posttraumatic symptoms instead. New behaviors may include episodes of screaming, throwing things, aggression and property destruction, hypervigilant reactions to normal changes, a lack of focus, inability to respond to people during the dissociative episode, nightmares, or expressing physical complaints. On the other hand, fear of abandonment or separation from the parent, fear of loss of life and other catastrophic thoughts can leave hard-core imprint on the young children's emotional biography. The resulting changes in functioning can facilitate disruptions in the previously established self-regulation and co-regulation patterns; the loss of the social circle; compromised school functioning; trouble with decision making; and language difficulties.

Developmental, Individual differences and Relationship based assessment and intervention 
Those familiar with Stanley Greenspan's model can't help noticing how the abovementioned coincides with the functional emotional developmental capacities (FEDC). DIRFloortime lends clinicians working with latency age children the developmental lens. In addition to the FEDC's, DIR ${ }^{\circledR}$ assessment creates the unique sensory, vestibular, proprioceptive, language, neuroceptive and motor profile of the child. All the assessed areas help to plan for the individually tailored interventions supporting and amplifying the said individual characteristics. Additionally, DIR ${ }^{\circledR}$ assessment specifically examines relationship with the primary caregiver and, when feasible, assesses caregiver's FEDCs. Understanding predominant levels of functional emotional development of the adult who's significant in the child's life helps therapists to approach issues of "the best fit" between a child and a parent with greater precision.

A therapeutic relationship as both a means and ends to successful treatment is pivotal to the DIR ${ }^{\circledR}$ informed work. It is only natural for the best parents and caregivers to want to "join in", "to share", or "to be with" the child. "Interaffectivity is mainly what is meant when clinicians speak of parental "mirroring" and "emphatic responsiveness" (Stern, 1985). When such primary relationships need to be recreated in the therapy room, a DIR ${ }^{\circledR}$-minded therapist takes on a role of witness to the child's raw emotion and listens intently to expression of special interests or concerns. The therapist makes him/herself readily available to manage fears, to help with down-regulation, and to open up uncomfortable conversations rather than avoid frightening topics or shutdown. Empathetic acceptance is the first step towards developing trust; trusting interactions can facilitate healing and restore missing steps in the developmental ladder. Yet another important dimension is the sense of mastery. If we are to work from the premise of Erik Erikson that school age children resolve issues of inferiority versus industry, it means that they indeed can greatly benefit from therapeutic relationship promoting a sense of competency.

Profound understanding of the individual differences opens new vistas in the clinical landscape. Many highly anxious children may struggle with issues around sensory reactivity that go unnoticed and unaddressed in the traditional psychotherapy. Sensory reactivity can put such children in the perpetual (or frequent) state of sensory overload, when anxious mood is further exacerbated by the malfunctioning ability to process and integrate sensory information. Helping children to recover from the emotional and sensory overload means decrease in self-blame, in polarized and inflexible thinking, anticipatory anxiety, and a sense of helplessness and inadequacy, in addition to creating optimal conditions for sensory integration.

Another important determinant is language capacity. Because of linguistic limitations of various nature (from the, age-appropriately so, limited vocabulary to problems of delayed speech development), children are shortchanged in their choice of neuro-integration tools when it comes to verbalization of experiences, worries or fears. As a result, instead of verbally labeling their prevailing "emotion of an hour" as anxiety, they present many changes in behavior, from school refusal to psychosomatic problems to behavioral storms.

In order to mend ruptures in the step-by-step functional emotional development and to have the FEDC's develop and grow to an age appropriate maximum, a therapist can offer a number of techniques to facilitate co-regulation, 
from precisely measured, tailored to the child's needs physical contact, to the use of timbre, pace and rhythm of interactions. Psychodynamic case formulation is being enriched by observations form the developmental angle. Relationship building starts with a therapeutic technique of following the patient's lead. Several working objectives listed below serve an overarching goal, to narrate (or play through) the experienced, anticipated or imagined catastrophic event and reestablish sense of safety:

- Validate emotions and experiences (don't downplay reality; respect "improbable", fantasy versions of what happened)

- Tailor own affect not to the content but to the child's affect

- Work face to face whenever feasible

- Tolerate high affect, anger and displacement of aggression

- Tolerate rigidity and rituals

- Tolerate silences and messes

- and, later, to normalize and generalize child's perception of the event, his/her role in it and an emotional aspect of the trauma/precipitating event:

- Extend circles of interaction (see the detailed explanation in "Engaging Autism" and other writings of S. Greenspan) superficial

- Don't concentrate on the plot and the choice of activity - go beyond

- Teach self-soothing and identify new routines needed

- Consider FEDCs: Move up and down the developmental ladder as

Another important aspect of work is building supports for the individual profile of the child:

- Adjust pace and rhythm

- Encourage motor planning and general executive planning

- Help to learn about his/her own sensory needs and preferences

Before proceeding to two clinical vignettes, the author would also like to note that, when we speak about anxiety, its precipitants and manifestations, the little studied important distinction is gender. Difference between girls and boys of the latency age is apparent at the level of presenting problems: while boys predominantly present with active defiance and acting out ("fighting"), girls turn to self-destructive behaviors of the "flight" and "freeze" spectrum. Although two cases that the author is about to present do not confirm to the above observation, the majority of the cases in the decades-long practice fall into two categories, boys referred by the school guidance counselors or teachers and girls brought in by perturbed parents. The author feels that this tendency is worth examining in the future.

\section{Sam: Living in the uncertain future}

I met friendly and chatty Sam, an only child in a loving and caring full family, when he was 8 , and proceeded to work with him until 10 years of age. He arrived to me with the diagnoses of Tourette's Syndrome, Attention Deficit Hyperactivity Disorder and Obsessive-Compulsive Disorder. His neurologist prescribed a daytime stimulant to help him attend to tasks in school. His mom related multiple evidence of poor self-regulation and complaints about his rigidity, 
incessant questioning and "clinginess." At intake, Sam related multiple fears and "bad dreams" centered around themes of abandonment and death. Sam's obsessive thinking, rumination and compulsive rearranging of toys and objects created mere obstacles to the normal flow of things at home, but his behavior in school seemed to be barely tolerable despite mother's constant involvement. At times, he needed emotional and even physical support throughout the school day. Issues and emergencies ranged from being bullied by other children (for instance, being called "a girl" because of avoiding sports and gross motor games, and because of his preference for bright "girly" colors in his clothes) to engaging in inappropriate touching behavior. As a result of his unmet proprioceptive needs, his unsolicited hugs could easily progress to punches.

Sam's difficulty in motor planning and executive functioning was overcompensated with exhausting rituals and verbose behavior. He had difficulty staying in bed at night, and parents had to partake in an elaborate nighttime routine of Sam's own invention to help him soothe and finally calm down enough so that he could fall asleep. Sam also had asthma and acid reflux, both conditions closely associated with the sympathetic vagal response, and both pointing to the underlying anxiety.

On the functional emotional developmental scale, Sam exhibited difficulties with self-regulation, seeing multiple perspectives, and demonstrated somewhat rigid use of language, while exhibiting excellent logical thinking and ability to connect ideas, as well as true concern for others, especially for his family members, and empathy, albeit on his own terms.

Deficits in Capacity 7 can be reframed as problems in the development of theory of mind. Can the theory of mind, an understanding of the fact that others' minds differ, be taught? This question continues to be a matter of debate. It should be noted that not being able to feel the feeling of the other or predict their response is commonly associated with lack of empathy. Contrary to this belief, Sam spent a lot of time worrying about others and whether they want to play with him or stay in his company precisely because of the insufficient understanding of the other's mind. It was because of his high emotional sensitivity and empathetic stance that he worked himself up to a chronic state of anxiety and self-doubt.

To gain quick access to Sam's fears of the day, we leaned heavily on his creativity. Sam would start each session with the drawing or making play dough figurines that would portray his "life now" (current worry) and "a future life", in a sense, representing hierarchy of fears. Initial drawings would be overcrowded with "decorative" doodling, distracting the viewer from the subject of the picture. Sam would get lost in detail and consequently demonstrate high anxiety seeing his own inability to complete the drawing.

Taking into account his interest in art and in elaborate, extended from week to week, projects, I created a sensory minded space with the "thinking corner" (two pillows propped against two walls in a corner, under straight angle) and the "hugging machine" (a heavy throw that Sam could wrap around whenever he "needed a hug", proprioceptive input). He would leave his unfinished projects in a safe place where no one else would touch them until our next play session and was happy to find them undisturbed the next week. Creating a safe space and sense of permanence proved helpful in building trust but also putting limits on our 
time together. Sam gradually started to accept limits at home and subsequently shortened the nighttime routine.

Catherine Pittman et. al. notes that "with compulsions, someone might find that they repeatedly engaging in a specific behavior which gives them temporary relief, but which they feel they must perform over and over. If you find yourself preoccupied with certain thoughts or compulsions and you have trouble getting past them, this is definitely a problem that arises from the cortex pathway" (2015). In this case, Sam's fears were interpreted as metaphor and taken seriously. To help Sam get "unstuck" and to switch off the anxious content that would disrupt his functioning and forced to use various self-soothing (dysfunctional) strategies, from physically clinging, thus providing sensory stimulation, to creating elaborate nighttime rituals, therapist and a parent united in validation. When his sensory profile was taken into account as well, we became able to jointly devise a plan of intervention whereas Sam learned about his own sensory profile and need for touch and figured out creative ways to regulate his proprioceptive system with help of sensory integration accessories. Bringing a weighted vest to school also helped the mother to begin conversation with school professionals about Sam's sensory needs and close connection between his behavioral storms and sensory dysregulation.

Sam's need for acceptance, coupled together with anxiety and repetitive behavior, made him an ideal candidate for various performance-based endeavors. He enjoyed singing and brightly colored clothing - and being on stage became a great venue for both interests. In addition to joining a school based performing arts program, mom also got him into voice lessons. Sam was finally relieved to hear that he, indeed, could be liked and even applauded to, and his self-esteem started to climb up. Greenspan (2006) aptly noted that mastery of own sensory system grows with information about specifics of one's reactivity. Sam became quite an expert in determining what intervention could truly help at the moment.

For the purpose of this paper, the author would like to discuss an episode involving Sam's mother's plans to undergo gastric bypass surgery. As she got on a strict diet and started to lose weight in preparation, she also became more active socially and rapidly developed new interests, including going back to school. In the individual session, she shared her fantasies about more fulfilling life outside of her routine of a wife and a mother and hopes of developing a stronger social persona.

Around that time, Sam produced a double drawing, of his family "now " and of the "future family". In the "future family " drawing, mom was depicted as a dotted line figure. Via therapist's running commentary, observations and reframing, Sam was assisted in further elaboration. He verbalized fear that his mother was becoming so thin that in the future she could totally disappear. When Sam's fear was brought up during the session with the mother, it became clear that she perceived his concern as the threat to her need to self-actualize rather than a legitimate fear It became urgent to help her move up to the capacity of taking in another person's perspective, the Capacity 7 on functional emotional developmental scale, so that she could emphasize with Sam's need to keep her emotionally connected through this, exciting to her but threatening to him, change. She was able to accept my reframing of Sam's anxiety as developmental crisis and commit to helping him verbalize fear of abandonment. We discussed 
Sam's worry in the joint session with mom who adamantly confirmed that she'd never disappear from the family life, no matter how thin and busy she 'd become. After his fears were examined in the, so to speak, broad light, I asked him to repeat the same drawing from time to time. Later versions of the "future life" drawing contained lesser amount of the "decorative" concentric circles and other distracting details, and themes became not catastrophic but rather optimistic (growing up, becoming rich, getting a pet etc.)

When we were about to terminate, Sam set a goal for himself to redecorate my office. In his zeal, he attached his "playdough installation " to a stack of my business cards.

"How do you think I feel looking at this?" I asked.

After a momentous pause, Sam replied, "You must be a little mad about your cards, but aren't you happy to see the rainbow colors?"

To me, it meant that he could recognize my reaction while also asserting with his own idea and therefore mastered the new functional emotional capacity.

Nikky: "An unwanted child"

Nikky, a 12-year old Caucasian girl, was brought to treatment by her mother because of aggression and behavioral storms at home, academic problems that eventually turned into school refusal, and "defiant behavior" across settings. Nikky was previously diagnosed with Oppositional Defiant Disorder. She was referred for therapy by a psychiatrist who was medicating her for attention deficit with Vyvanse for some 6 years, and who finally asserted that psychotherapy would be a must.

Nikky lived with her biological mother, stepfather and twin half-sisters. Nikky's biological father resided across the country and took her for visits two to three times a year. Her mother disclosed that Nikky's relationship with the stepfather and siblings was so poor that they all were constantly tense, waiting for her to lash out verbally and physically at any moment.

When schoolteachers were contacted, they all described her as a passive, even listless student who "seems to want to fail".

During the initial session, Nikky, an underweight and short for her age blond girl, was dressed age inappropriately, wearing a unicorn themed top that appeared a size too small. While the mother recounted Nikky's multiple misdemeanors, Nikky loudly protested, refuting each item, from "unprovoked" fights with the stepfather to "being hated by siblings " (as per Nikky, her young sister and brother were "brainwashed " by both parents and instructed to ignore her). Her vocabulary was surprisingly big yet grossly inappropriate for a 12-year old; for example, she used a slang word for "delinquency" that impressed me as a police jargon.

Nikky was reportedly a healthy child, except for frequent urinary infections. Day- and nighttime incontinence across settings was disclosed, but mom felt that it was Nikky's way of "punishing her." Nikky responded with the rageful scream; she was clearly embarrassed to talk about enuresis. When I asked about Nikky 's strengths, mom replied with surprise that she was born a difficult child but became truly unbearable by the age of four. Incidentally, this was the time when her biological parents' divorce was finalized, and when mom remarried. Mom, sensing my disapproval, added that Nikky's life is lax and 
luxurious, and she has the whole floor of the house to herself and therefore should not complain.

At the time Nikky happened to be on indefinite punishment for failing school and "showing disrespect" at home, and her TV and phone privileges were taken from her. She reportedly spent her time at home staring at the wall where her TV used to hang. Because of the "no TV" punishment, she was no longer allowed in the living room, her parents ' bedroom and her siblings' room, and stayed in her basement room (that was what her mom had referred to as "Nikky 's own floor").

When I asked Nikky about her wants and needs, she requested that her mother paid attention not only to negative behaviors but, at least sometimes, to positive; moreover, she stated that she didn't want to be "punished when something good was accomplished".

Lyons-Ruth and Jacobitz (2008) write about parental unavailability as predictor of regulation problems. Early disintegration of the family laid foundation to later difficulties in self-regulation even at times when Nikky wanted to be calm and emotionally present (a basic requirement for engaging with others). It is important also to acknowledge that mother's stand in the conflict between her husband and Nikky clearly vacillated towards her husband's view of the problem. All Nikky's actions and emotional responses, including psychosomatic symptomatology (enuresis), were invariably interpreted as attention seeking.

Nikky's functional emotional developmental capacities were visibly delayed: she had difficulty co-regulating with others and overall sustaining attention on the outside world, busily recounting past hurts and injustices; her interactions with others were limited to family feuds. She had difficulty sustaining longer chains of interactions if they fell outside of her immediate concerns. She had no delays in higher level capacities and demonstrated sound logic and good verbal capacities, demonstrating a special gift for biting remarks along with age appropriate understanding of moral standards and requirements. It appeared, though, that she couldn't do her schoolwork, forge friendships or pursue interests because of the intense separation anxiety. As per FEDC scale, the gray area thinking capacity could have emerged by the age of 10, but Nikky experienced great difficulty seeing "shades of gray" in people's behavior and avoiding quick and harsh judgment.

We started work in joint sessions, trying to verbalize the essence of conflicts and formulate problems. The best way to be with Nikky would be joining in with her anger while also down-regulating via lower pitch and volume of speech and establishing a less stimulating sensory environment in the sessionand, indeed, I began to feel as angry as she did at different moments in the course of treatment, for example, hearing that her mother never followed up with the urologist. Therefore, Nikky's feelings received validation on the nonverbal level. Additionally, I demonstrated a very different take on anger: not wailing or yelling but assertively addressing the issue. Quite soon, both Nikky and her mother came to view me as Nikky's ally and protector. Nikky's general demeanor noticeably changed, and she'd even master an occasional guarded smile.

Nikky was the most unlikely candidate for play therapy of any sort: she did not have the slightest interest in motor play, nor was she ready for symbolic play. It was unclear if Nikky was ever played with. Most of all, she was preoccupied with her current situation and with the projected altercations and 
"traps" set for her by the hateful stepfather. I offered Nikky to divide the session time in two halves: "We will discuss what worries you in the first half and proceed to play a game of my liking in the second." While it wasn't a classical Floortime approach to play, nor was it a traditional psychotherapeutic technique, such directive was the only way to expose Nikky to the idea of playful interaction. Given a choice of activities, she attempted a board game but found it boring and hard, and rules confusing. I offered, "Almost like schoolwork." Indeed, Nikky later recognized that her preoccupation with events at home was highly distracting during the school day, and she barely followed.

"What do you think we can play with?" She reluctantly chose family puppets but didn't know what to do with them. She held several puppets in her lap while I was setting up the doll house. I offered to put a daddy puppet on my hand, and she reluctantly agreed. She finally dropped her puppets in the middle of the "room". I suggested that it was probably a mealtime, and they all could be seated by a table. When my puppet also approached the table and called out, "Hi kids, I'm home, " she hyperventilated and got up to leave my office. Mom attempted to stop her, but I let her leave and proceeded to work with mom.

During the next couple of sessions, we worked on eliciting Nikky's fears and establishing collaboration. However, it looked like her relationship with mom was unsalvageable.

Eventually, I requested to see both parents, without Nikky. Mom was highly hesitant, and eventually said that her husband had no interest in helping Nikky. I asked for his phone number and in a few days called to personally invite him to the session. Eventually, they both came in.

Nikky's stepfather, a tall, imposing, young looking police officer, opened the floor with the list of complaints. Unlike the mother who was unhappy with Nikky's schoolwork, he was mostly complaining about her attitude. It sounded like he was irked by the looks that she'd cast, reading into her gestures and silences. I also offered to problem solve as it came to sleeping arrangements, because Nikky reportedly was freezing at night, which didn't help her enuresis. The stepfather explained that Nikky was moved to the basement fairly recently because she was screaming at night, and he wouldn't be able to have a normal night sleep. Screaming? Yes, screaming over Skype, chatting with her father.

As I reframed some of his comments about his stepdaughter, the mother suddenly started to object some of his hostile remarks. I summarized, "It sounds like most of the problems are centered around the stepfather-stepdaughter relationship; no one is happy in your household because of it, and there's no way to reconcile. Would it benefit everyone if Nikky was to move to her dad's home?"

They both looked surprised and somewhat shocked. I asked them to share their feelings. Then, the stepfather said that seeing Nikky go would bring him enormous relief and make his family life blissful. The mother said, however, that she was confused, yet would explore this possibility with her ex.

When Nikky came for her next session, I tried to explore her relationship with her dad. Nikky clearly idealized her, rarely seen, dad. As we discussed her memories of the recent visit, I offered to bring out puppets and replay these scenarios.

The following week, Nikky came in and reached for the puppets. I restored the setting from the previous session, yet challenged Nikky to elaborate and invent 
new situations: what would it be like to walk to school with her dad, what food she could learn to cook etc. In a few days, Nikky's mom called and requested an individual session. She shared that she had several heated interactions with her husband, and finally told him that "she could have another husband, but her daughter is hers for life."

"You put us on edge, but now I see what I want to achieve... I didn't realize that she wasn't happy."

I suggested to find out from Nikky what she wanted. My goal was to empower Nikky and give her actual control over her life (and maybe eventually over her bladder...). For the first time, mom appeared interested in Nikky's opinion. But first I saw Nikky one on one and shared options with her. Nikky wasn't surprised: "My mom told me already that I can choose where I can live."

"Have you made the decision?"

"I decided to stay with my mom. After all, she is my mom and I think she'll be lonely without me, "

To summarize this case vignette, early disruption in attachment pattern and subsequent anxiety manifesting itself through psychosomatic symptoms (delays in physical development, enuresis) and interchange of SNS "fight" or "freeze" modes were addressed via meeting the need "... to communicate with the traumatized individuals around anything they want to communicate, with the simplest gestures - exchanging smiles, or frowns or using hand gestures" (Greenspan , 2007). Paradoxical interventions with parents along with active recruitment of mom's empathy proved effective in reengaging Nikky. The mother and daughter eventually became able to restore their primary relationship, overcome rupture in attachment, and start the slow and painstaking process of repair. Whereas the task "to reshape microcommunication and find a more flexible (gentle but expressive) tone in an "exaggerated" family, where an elevated (and often irritated) affect is used in most domestic situations" (Itskovich, 2019) continues to bear the utmost importance for Nikky's interactions with her mom, the alleviation of the chronic state of inferiority and shame paved the road to age appropriate separation and to replicating positive relationships outside of Nikky's home. Stanley Greenspan pointed out that "we have to reestablish not only safety and security in the physical sense - protection from the elements or protection from an abuser or protection from the bombs or the guns but we have to reestablish a nurturing relationship with somebody..." (2007).

\section{Summary}

Application of the model for the purposes of play and talk therapy with anxious children entails

- Presuming competence

- Tolerance for negative affect

- Continuous flow of emotional signaling that creates a safe space ("the worst is over")

- Allowing for the story to unfold and change as the event is being processed

DIR ${ }^{\circledR}$-informed treatment focuses on relationship building while using clinically valid information on individual's unique profile and functional emotional developmental capacities. It has the potential of becoming truly invaluable if added, for the case formulation purposes, to a psychodynamic 
toolbox. But most importantly, DIR ${ }^{\circledR}$ calls for respect of individual differences and focuses on the healing and on wholesome child-adult relationship that can reconnect the fabric of the child's development and emotional growth that's been previously disrupted by anxiety and trauma. Anxiety can be pervasive but so it the relationship.

\section{References}

Allen, J.G., Bateman, A.W. and Fonagy, P. (2008). Mentalizing in Clinical Practice. American Psychiatric Pub.

Anxiety and Depression Association of America, 2019, website. https://adaa.org

Beauchaine, T.P. , Gatzke-Kopp, L. and Mead. H. K. (2007). Polyvagal Theory and Developmental Psychopathology: Emotion Dysregulation and Conduct Problems from Preschool to Adolescence. Biological Psychology. Feb; 74(2): 174-184.

Bandelow, B., Michaelis, S. (2015). Epidemiology of anxiety disorders in the 21st century. Dialogues on Clinical Neuroscience. Sep; 17(3): 327-335.

Bateman,A.W., Fonagy, P. (2006). Mechanisms of change in mentalization-based treatment of BPD. Journal of Clinical Psychology. Apr 62(4):411-30.

"Data and Statistics on Children's Mental Health | CDC." Centers for Disease Control and Prevention, https://www.cdc.gov/childrensmentalhealth/data.html.

Erikson, E. H. (1950). Childhood and Society. W. W. Norton and Co., 1963.

Geller, S.M., Porges, S.W. (2014). Therapeutic Presence: Neurophysiological Mechanisms Mediating Feeling Safe in Therapeutic Relationships. Journal of Psychotherapy Integration, Vol. 24, No. 3, 178-19.

Greenspan S.I., Wieder S. (2006). Engaging Autism: Using the Floortime approach to help children relate, communicate, and think. Cambridge, MA, US: Da Capo Press.

Greenspan, S.I., Greenspan, N.T. (1985). First feelings: Milestones in the emotional development of your infant and child from birth to age 4 . New York: Viking Press.

Greenspan, S.I. (2007). How to Help Infants, Children, and Adults Deal with Trauma. Web-Based Radio Show, ICDL. Bethesda, MD.

Hecht, D. (2013). The Neural Basis of Optimism and Pessimism. Experimental Neurobiology, 2013 Sep;22(3):173-199.

Herrington, J. D.; Maddox, B. B.; Kerns, C. M.; Rump, K.; Worley, J. A.; Bush, J. C.; McVey, A. J.; Schultz, R. T.; Miller, J. S. (2017). Amygdala Volume Differences in Autism Spectrum Disorder Are Related to Anxiety. Journal of Autism and Developmental Disorders, v47 n12 p3682-3691 Dec.

Itskovich, G. (2019). On Affective States and the Use of Affect in DIRFloortime Clinical Practice. Autism and Developmental Disorders (Russia). Vol. 17. No 2 (63).

Lyons-Ruth, K. and Jacobitz, D. (2008). Attachment disorganization: Genetic factors, parenting contexts, and developmental transformations from infancy to adulthood. In: Cassidy, J. and Shaver, P.R., Eds., Handbook of Attachment. Theory, Research, and Clinical Applications. Guilford Press, New York, 666-697. 
Pittman, C, Karle, E. M. (2015). Rewire Your Anxious Brain: How to Use the Neuroscience of Fear to End Anxiety, Panic, and Worry. Oakland, CA: New Harbinger Publications, 232.

Porges, Stephen W. (2009). Reciprocal influences between body and brain in the perception and expression of affect: A polyvagal perspective. In D. Fosha, D. J. Siegel, \& M. F. Solomon (Eds.) The healing power of emotion: Affective neuroscience, development, clinical practice. New York: W.W.Norton \& Co., 9.

Siegel, D. (2012). The Whole-Brain Child. New York: Bantham.

Stern, D. (1985). The Interpersonal World of the Infant. Basic Books.

UNISEF. Child displacement. December 2018 document, website. https://data.unicef.org/topic/child-migration-anddisplacement/displacement/

Winnicott, D. W. (1958). Through Paediatrics to Psycho-Analysis. In: Collected Papers, Introduction by Manuel Khan. London: Karnac Books. 